they are unacquainted with the work of games theorists and welfare economists. Hare, however, shows himself well aware of the difficulties; and there is great force in his contention that they face all moralists who attach any importance to doing social good or preventing social harm, and not just utilitarians.

Part III seeks to show why we should go in for critical thinking, conceding that there is no logically compelling argument against the amoralist, but endorsing a probable argument in prudence against bringing up children to be such. It is further argued that it is logically impossible for there to be a consistent, non-utilitarian fanatic. Here, as throughout, it is maintained that critical moral reasoning is both philosophically justified in terms of the concept of moral judgments as universalizable prescriptions and capable of directing ideally acute, sensitive, fully-informed people to rational solutions to practical questions. Actual human beings, of course, fall short; but rational solutions remain possible in principle.

Hare is unquestionably the most influential British moral philosopher of the last 30 years. His book will inevitably be of immense interest to fellow philosophical practitioners, who will want to see how he has qualified and developed his views. Hare, however, clearly hopes to reach a wider public, feeling that 'unless some way is found of talking about [urgent practical issues] rationally and with hope of agreement, violence will finally engulf the world'. I am sure that an understanding of the present book would greatly improve public discussion; but I fear that it may not exert the wide direct influence that it should. Hare is an exceptionally careful thinker and a clear-headed writer; but his book is not wholly accessible to the lay reader. It comes across as a report on work in progress, shaped as often as not by the objections of critics, and compressed by a notable reluctance to bore the reader by repetition of other writings or extended discussion of matters not central to the main argument. These intuitions have merit; but critical thought should convince the author that he could do good by expressing himself at greater length and in a more relaxed and less argumentative manner. $\mathrm{He}$ acknowledges debts to Kant and Mill. I think he could surpass the rigour of the former in a work as widely readable as the Utilitarianism or Liberty of the latter.

PROFESSOR R F ATKINSON Department of Philosophy The University of Exeter

\section{Justice and Health Care}

Ed Earl E Shelp

Holland, D Reidel Publishing Co

(Volume 8 of Philosophy and Medicine series)

Dfl 60 US $\$ 31.50$ (paperback Dfl 30 US \$14.95)

The dominant emphasis in medical ethics during the last decade has been on specific moral problems of individual or small group decision-making. Analysis has concentrated on issues such as abortion, fetal research, care of the terminally ill, drug abuse and organ transplantation etc. The objective has been to articulate and assess the parameters for moral decision-making in these specific contexts of medical care. Insofar as bioethicists have stressed analysis of these 'micro' issues, there has been a corresponding lack of sustained analysis of the institutional character of medicine and health care provision - the 'macro' structure within which the micro issues arise. The Shelp volume attempts to correct the imbalance of focus by $I$ ) examining the health care institutions within which micro problems arise; 2) investigating the larger array of institutions of which the health care sector is only one part. Key concepts examined throughout the volume are those of 'justice', 'right', and their relevant application to the domain of 'health care'. But justice and rights considerations can only be clarified by examining various theories in terms of which certain claims about justice and rights are made and by means of which these claims can be defended. Without at least an implicit ethical theory or a theory of justice, certain questions cannot be coherently asked much less answered.

Such questions include: Is there a right to health care? What does such a right mean and imply with respect to an array of other basic rights we try to defend? What is the content of a right to health care? Are we claiming a right to free provision of medical care in crisis situations of disease and this for all members of society in an equal way or do we also include under the umbrella of this 'right' free access to the full range of technological provisions in medicine including such items as human in vitro fertilisation, heart transplants and cosmetic surgery (to name only a few of the procedures available which many would consider non-essential under a right to health care)? The parameters of rights claims are not self-evident and the essays in this volume show no presumption that their analyses offer final resolutions of these complex questions. They do, however, highlight some of the essential questions that would need to be asked in order to come to some plausible view as to the resolution.

Another question concerns the socio-economic and ethical issue of priorities. The priority question arises at two levels: the priority of health care relative to other goods and needs, and the order of priority of various forms of health care. While the issue of priorities is complex in terms of theoretical considerations it is no less so at the level of practical decision-making in any society faced with limited economic resources. Thus a third question, which asks about the justice or injustice of current health care systems, is a question which presupposes that we opt for a theory of justice that can argue for or against a universal right to health care and likewise provide a basis for defending priority decisions. It is not surprising, then, that the present volume on justice and health care will be considered as weak or as strong as are the theories of justice proposed to defend the various claims both at the micro and macro level of health care allocations.

DOLORES DOOLEY-CLARKE Department of Philosophy University College Cork, Ireland

\section{The Rights of Doctors and Nurses and Allied Health Professionals}

\author{
G J Annas, L H Glantz and B F Katz \\ New York, Avon Books \\ $\$ 3.95$
}

Doctors and nurses might be forgiven for believing that they have obligations and other people have rights so it was with some surprise that I received this book for review. My surprise was heightened when I saw that the cover described it as an 'American Civil Liberties Union Handbook'.

The book was suggested following one on the rights of hospital patients by one of the authors and from time to time the impression is given that the authors are more at home speaking of a doctor's 